\title{
Electron band alignment at the interface of (100)GaSb with molecular-beam deposited $\mathrm{Al}_{2} \mathrm{O}_{3}$
}

\author{
V. V. Afanas'ev, ${ }^{1, a)}$ H.-Y. Chou, ${ }^{1}$ A. Stesmans, ${ }^{1}$ C. Merckling, ${ }^{2}$ and X. Sun ${ }^{3}$ \\ ${ }^{1}$ Department of Physics and Astronomy, University of Leuven, B-3001 Leuven, Belgium \\ ${ }^{2}$ IMEC, Kapeldreef 75, B-3001 Leuven, Belgium \\ ${ }^{3}$ Department of Electrical Engineering, University of Leuven, B-3001 Leuven, Belgium \\ and Department of Electrical Engineering, Yale University, New Haven, Connecticut 06520, USA
}

(Received 24 December 2010; accepted 12 January 2011; published online 14 February 2011)

\begin{abstract}
From internal photoemission and photoconductivity measurements at the (100) $\mathrm{GaSb}_{2} \mathrm{Al}_{2} \mathrm{O}_{3}$ interface, the semiconductor valence band is found to be $3.05 \pm 0.10 \mathrm{eV}$ below the oxide conduction band. This band alignment corresponds to conduction and valence band offsets of $2.3 \pm 0.10$ and $3.05 \pm 0.15 \mathrm{eV}$, respectively. These results indicate that the valence band in $\mathrm{GaSb}$ lies energetically well above the valence band in $\operatorname{In}_{x} \mathrm{Ga}_{1-\mathrm{x}} \mathrm{As}(0 \leq \mathrm{x} \leq 0.53)$ or InP, suggesting the possibility of fabrication of hole quantum-well channel structures. (C) 2011 American Institute of Physics. [doi:10.1063/1.3549878]
\end{abstract}

Thanks to its high bulk hole mobility approaching $1000 \mathrm{~cm}^{2} \mathrm{~V}^{-1} \mathrm{~s}^{-1}$ at $300 \mathrm{~K}$, gallium antimonide $(\mathrm{GaSb})$ is considered to be a feasible candidate for high-speed p-channel metal-oxide-semiconductor (MOS) transistors which can easily be integrated with arsenide-based n-channel $\mathrm{A}_{\mathrm{III}} \mathrm{B}_{\mathrm{V}}$ devices. ${ }^{1,2}$ This scheme allows one to avoid crosscontamination problems as expected, for instance, in the case of combination with $\mathrm{SiGe}$ - or Ge-based p-channels. In particular, the quantum-well (QW) channel devices with a highpermittivity (high- $\kappa$ ) oxide gate insulator are expected to offer significant gains. The hole QW structure would require the valence band (VB) in GaSb to lie at a higher energy than the VB top of the arsenide semiconductor used in the n-channel device, e.g., $\operatorname{In}_{\mathrm{x}} \mathrm{Ga}_{1-\mathrm{x}}$ As or InAs. ${ }^{3}$ Recent results regarding electron band alignment at interfaces between (100) $\mathrm{In}_{\mathrm{x}} \mathrm{Ga}_{1-\mathrm{x}} \mathrm{As}$ and high- $\kappa$ oxides $\left(\mathrm{Al}_{2} \mathrm{O}_{3}, \mathrm{HfO}_{2}\right)$ suggest that variation of $\mathrm{x}$ from 0 to 0.75 has no major effect on the semiconductor VB energy. ${ }^{4,5}$ By contrast, a considerable $(>0.5 \mathrm{eV})$ downward shift of the $\mathrm{VB}$ top compared to the arsenide case is found at the (100) $\mathrm{InP} / \mathrm{Al}_{2} \mathrm{O}_{3}$ interfaces. $^{6}$ These results suggest that the VB top energy adjustment can be achieved by changing the group-V component, and a heavier group-V anion like $\mathrm{Sb}$ might deliver the $\mathrm{VB}$ top energy desired for the QW hole channel. To put this concept on a solid experimental ground we determined the (100) $\mathrm{GaSb} / \mathrm{Al}_{2} \mathrm{O}_{3}$ interface band alignment using internal photoemission (IPE) and photoconductivity (PC) spectroscopy experiments. The results show that, indeed, replacement of As by $\mathrm{Sb}$ results in $\approx 0.4 \mathrm{eV}$ upshift of the VB top in the Ga-based $\mathrm{A}_{\mathrm{III}} \mathrm{B}_{\mathrm{V}}$ semiconductor as referenced, all, to the same energy level of the amorphous $\mathrm{Al}_{2} \mathrm{O}_{3}$ conduction band (CB) bottom. In addition to revealing a fundamental trend in the $\mathrm{A}_{\mathrm{III}} \mathrm{B}_{\mathrm{V}}$ semiconductor/oxide band alignment, the above observation hints the possibility of hole QW channel engineering by varying the group- $\mathrm{V}$ anion.

Oxidation of $\mathrm{GaSb}$ during oxide deposition poses a significant challenge because $\mathrm{A}_{\mathrm{III}} \mathrm{B}_{\mathrm{V}} /$ high- $\kappa$ oxide studies indicate that the formation of a narrow-gap interlayer (IL) may result in interface barrier lowering, thus complicating reli-

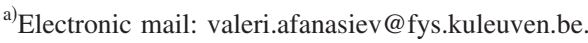

able extraction of the fundamental band offsets. ${ }^{4-7}$ To avoid this problem, we limited the supply of oxidant to the semiconductor surface by applying the molecular-beam epitaxy (MBE) technique to deposit amorphous $\mathrm{Al}_{2} \mathrm{O}_{3}$ thin films on (100)GaSb layers epitaxially grown on (100)InP substrates. Prior to $\mathrm{Al}_{2} \mathrm{O}_{3}$ deposition the $\mathrm{GaSb}$ surface exhibits a streak $(1 \times 3)$ reconstruction as observed by electron diffraction. The $10 \mathrm{~nm}$ thick alumina layer was grown from evaporated $\mathrm{Al}$ and atomic oxygen under an overall pressure of 3 $\times 10^{-6}$ Torr with the substrate kept at $50{ }^{\circ} \mathrm{C}$. ${ }^{8}$ MOS capacitors of $0.5 \mathrm{~mm}^{2}$ area were fabricated by thermoresistive evaporation of semitransparent $13-15 \mathrm{~nm}$ thick $\mathrm{Au}$ or $\mathrm{Al}$ electrodes in vacuum. These capacitors were used in the IPE and PC measurements carried out at room temperature in the photon energy $(\mathrm{h} \nu)$ range $2.0-6.8 \mathrm{eV}$ with a constant spectral resolution of $2 \mathrm{~nm}$. The quantum yield (Y) was determined by normalizing the measured photocurrent to the incident photon flux. ${ }^{9,10}$ The spectral dependences of the yield were analyzed to determine the energy thresholds for electron transitions delivering free charge carriers to the insulating oxide.

An example of the yield spectral curves is shown in Fig. 1(a) for a p-type (Si-doped, $\mathrm{n}_{\mathrm{a}}=3 \times 10^{18} \mathrm{~cm}^{-3}$ ) $\mathrm{GaSb} / \mathrm{Al}_{2} \mathrm{O}_{3} / \mathrm{Au}$ sample. The spectra measured under positive bias (open symbols) show field-independent features at $\mathrm{E}_{0}{ }^{\prime}=3.3 \mathrm{eV}$ and $\mathrm{E}_{2}=4.1 \mathrm{eV}$, coinciding in energy with excitation of direct optical transitions between high-symmetry points in the Brillouin zone of GaSb, i.e., $\Gamma_{8}^{\mathrm{V}} \rightarrow \Gamma_{7}^{\mathrm{C}}$ and $\mathrm{X}_{5}^{\mathrm{V}}$ $\rightarrow \mathrm{X}_{3}^{\mathrm{C}}$, respectively. ${ }^{11,12}$ This observation indicates that the photocurrent observed in the spectral range $\mathrm{h} \nu=3-5 \mathrm{eV}$ is due to electron IPE from the VB of GaSb into the alumina $\mathrm{CB}$. As no optical signatures of $\mathrm{GaSb}$ are found in the spectra taken under negative bias [filled symbols in Fig. 1(b)], the photocurrent observed in this case is likely caused by electron IPE from Au. This conclusion is confirmed by the shift of the IPE spectral threshold by $\approx 1 \mathrm{eV}$ to lower $\mathrm{h} \nu$ when $\mathrm{Au}$ is replaced by $\mathrm{Al}$ [symbols and $\square$ in Fig. 1(b), respectively]. Irrespective of the metal used, at $\mathrm{h} \nu>6 \mathrm{eV}$ the photocurrent spectra at both orientations of the electric field in the oxide reveal the onset of intrinsic PC. The spectral threshold $\mathrm{E}_{\mathrm{g}}\left(\mathrm{Al}_{2} \mathrm{O}_{3}\right)=6.1 \pm 0.1 \mathrm{eV}$ found from $\mathrm{Y}^{1 / 2}-\mathrm{h} \nu$ plots 


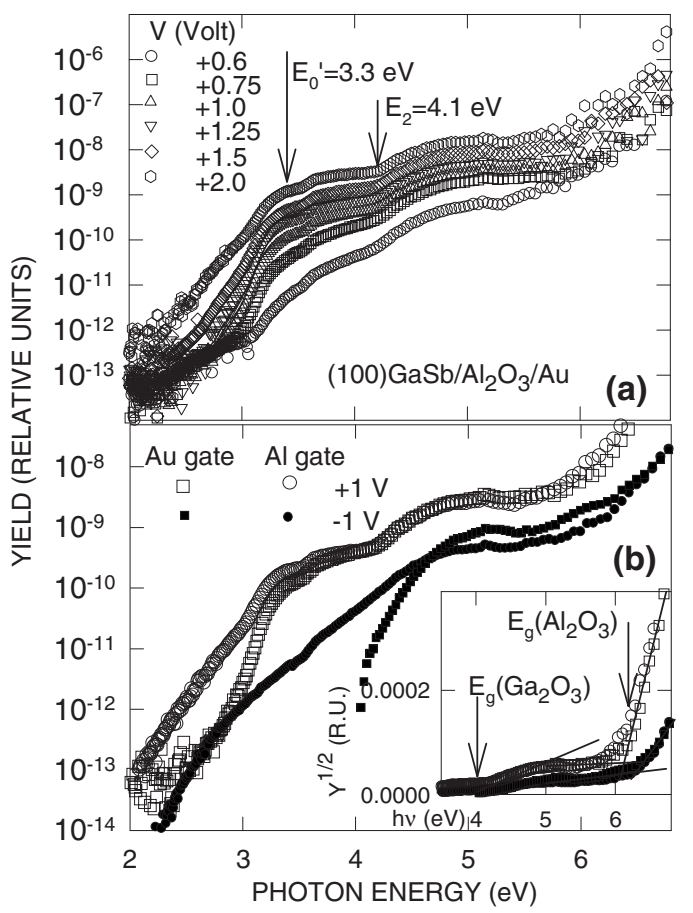

FIG. 1. (a) Logarithmic plot of the quantum yield as a function of photon energy measured on a p-type $(100) \mathrm{GaSb} / \mathrm{Al}_{2} \mathrm{O}_{3}(10 \mathrm{~nm}) / \mathrm{Au}(13 \mathrm{~nm})$ sample under different values of the voltage $(\mathrm{V})$ applied to the metal electrode. Arrows mark the energies of direct optical transitions within the GaSb crystal. (b) Logarithmic plot of the quantum yield as a function of photon energy as measured on p-type (100)GaSb MOS samples with Au (squares) and Al (circles) top electrodes. The inset illustrates the determination of the PC spectral thresholds from the $\mathrm{Y}^{1 / 2}-\mathrm{h} \nu$ plots. Lines guide the eye; arrows mark the inferred band gap energies.

[cf. inset in Fig. 1(b)] agrees with the results for a- $\mathrm{Al}_{2} \mathrm{O}_{3}$ layers grown by a variety of techniques on $\mathrm{Si}$ or other semiconductors. ${ }^{4,6,7}$ The PC spectra ( $\mathrm{Y}^{1 / 2}-\mathrm{h} \nu$ plots) also reveal a weak photocurrent with spectral threshold close to band gap width of $\mathrm{Ga}_{2} \mathrm{O}_{3}, \mathrm{E}_{\mathrm{g}}\left(\mathrm{Ga}_{2} \mathrm{O}_{3}\right)=4 \mathrm{eV}$, ${ }^{13}$ with the quantum yield roughly two orders of magnitude below that of the $\mathrm{Al}_{2} \mathrm{O}_{3}$ PC. This yield ratio allows us to roughly estimate the amount of $\mathrm{Ga}$ oxide as limited to about $1 \%$ of the $\mathrm{Al}$ oxide, i.e., below one monolayer. In support of this conclusion, neither x-ray photoelectron spectroscopy (XPS) nor cross-sectional transmission electron microscopy (TEM) could reveal a $\mathrm{Ga}$ oxide IL between $\mathrm{GaSb}$ and $\mathrm{Al}_{2} \mathrm{O}_{3}$ (not shown), indicating insignificant GaSb oxidation during lowtemperature MBE growth.

To determine the spectral thresholds, the IPE data measured under positive bias were plotted in $Y^{1 / 3}-\mathrm{h} \nu$ coordinates as suggested by Powell, ${ }^{14}$ with the results illustrated in Fig. 2. The curves measured under low bias voltages allow one to determine the energy onset of electron IPE from the top of GaSb VB to the CB of alumina as marked by the vertical arrow $\Phi_{1}$. With the applied oxide field increasing, a second lower threshold, $\Phi_{2}$, characterized by strong field dependence becomes visible. To determine the intrinsic zero-field interface energy barriers, the spectral thresholds were plotted as a function of the square root of the average electric field in the oxide (the Schottky plot). ${ }^{9}$ To account for the built-in electric field associated with the metal-GaSb work function difference, the field strength was calculated by subtracting the voltage at which the IPE current starts to appear from the applied bias and then dividing the result by the oxide thick-

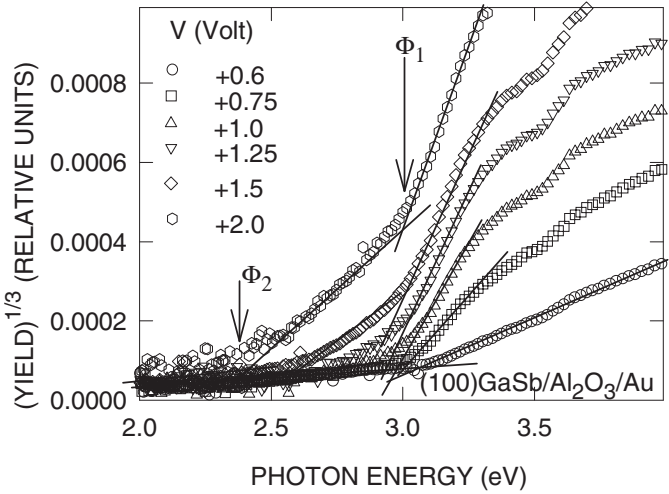

FIG. 2. Determination of the spectral thresholds of electron IPE from GaSb into $\mathrm{Al}_{2} \mathrm{O}_{3}$ using the $\mathrm{Y}^{1 / 3}-\mathrm{h} \nu$ plots. Lines guide the eye; arrows mark the inferred thresholds $\Phi_{1}$ and $\Phi_{2}$.

ness. The results shown in Fig. 3 indicate that the threshold $\Phi_{1}$ is weakly field-dependent which would be consistent with direct electron IPE from $\mathrm{GaSb}$ into the $\mathrm{CB}$ of $\mathrm{Al}_{2} \mathrm{O}_{3}$. Then the zero-field barrier height of $\Phi_{1}=3.05 \pm 0.10 \mathrm{eV}$ corresponds to the energy difference between the GaSb VB top and the $\mathrm{Al}_{2} \mathrm{O}_{3} \mathrm{CB}$ bottom. Using the value of $0.73 \mathrm{eV}$ as the gap width of $\mathrm{GaSb}$ and $6.1 \mathrm{eV}$ as the gap of alumina found from the PC spectra [Fig. 1(b)], the CB and VB offsets at the $(100) \mathrm{GaSb} / \mathrm{Al}_{2} \mathrm{O}_{3}$ interface follow as $2.3 \pm 0.10$ and $3.05 \pm 0.15 \mathrm{eV}$, respectively.

From Fig. 3, the lower threshold $\Phi_{2}$ is seen to be significantly lowered when the field increases, ultimately becoming $\approx 0.7 \mathrm{eV}$ lower than $\Phi_{1}$. A similar effect can also be seen when the Au top electrode is replaced by $\mathrm{Al}$ [cf. symbols $\square$ and $\bigcirc$ in Fig. 1(b)] because the lower work function of $\mathrm{Al}$ results in a higher strength of the electric field in the alumina. As the PC and structure-sensitive TEM and XPS analyses could detect no IL, the origin of the barrier lowering is likely associated with penetration of the electric field in the $\mathrm{p}^{+}$-type photoemitter. The surface depletion of $\mathrm{p}^{+}-\mathrm{GaSb}$ under positive bias is indicated by capacitance-voltage $(\mathrm{CV})$ measurements (not shown). Then, the field induces a downward bend bending in $\mathrm{GaSb}$ at a depth comparable to the inelastic mean free path of photoexcited electron, like it is observed in the case of $\mathrm{p}^{+}$-doped $\mathrm{Si}$ (see, e.g., Fig. 2.1.3 in Ref. 10). As illustrated in the inset in Fig. 3, driven by positive bias electrons excited deeper in the GaSb layer will acquire additional energy associated with the band bending in

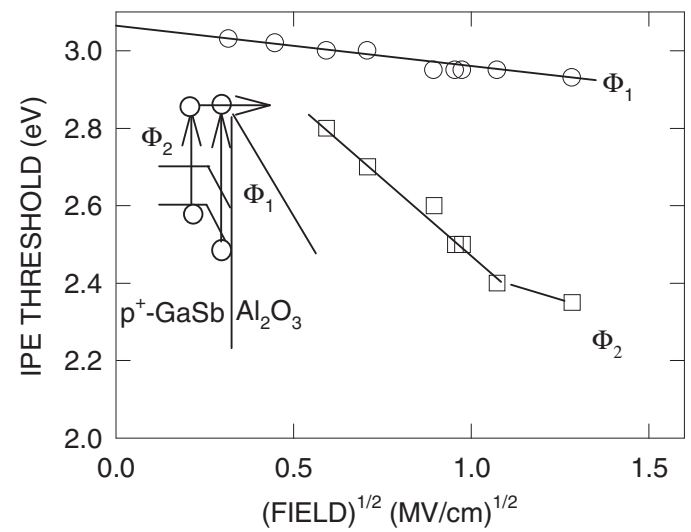

FIG. 3. Schottky plot of the inferred spectral threshold of electron IPE from $\mathrm{GaSb}$ into $\mathrm{Al}_{2} \mathrm{O}_{3}$. The inset shows the scheme of the observed electron transitions. Lines guide the eye. 


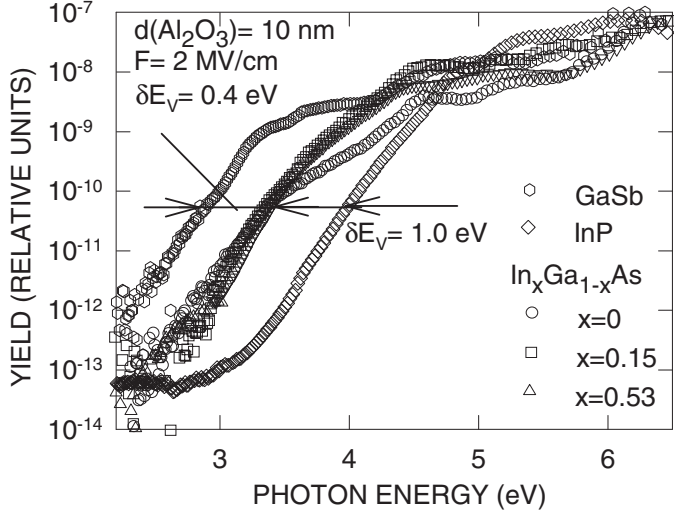

FIG. 4. Comparison of the yield spectra for several $A_{I I I} B_{V}$ semiconductors in contact with a $10 \mathrm{~nm}$ thick $\mathrm{Al}_{2} \mathrm{O}_{3}$ insulating layer measured under equal strength of electric field in the oxide (positive bias). The inferred variations in the semiconductor $\mathrm{VB}$ top energies relative to the common reference level of $\mathrm{Al}_{2} \mathrm{O}_{3} \mathrm{CB}$ bottom are indicated by arrows.

the narrow space-charge layer of the semiconductor. This means that electron IPE into the $\mathrm{Al}_{2} \mathrm{O}_{3} \mathrm{CB}$ becomes possible at lower photon energy than IPE from electron states at the surface of GaSb. In the limiting case of high electric field, the band bending is expected to become comparable to the gap width of $\mathrm{GaSb}(0.73 \mathrm{eV}$ at $300 \mathrm{~K})$, which agrees with the observed difference between the IPE thresholds $\Phi_{1}$ and $\Phi_{2}$.

As a final step we compare in Fig. 4 electron IPE yield spectra of $(100) \mathrm{GaSb} / \mathrm{Al}_{2} \mathrm{O}_{3}$ to those of the previously studied (100) $\operatorname{In}_{\mathrm{x}} \mathrm{Ga}_{1-\mathrm{x}} \mathrm{As} \quad(0 \leq \mathrm{x} \leq 0.53) / \mathrm{Al}_{2} \mathrm{O}_{3} \quad$ and (100) $\mathrm{InP} / \mathrm{Al}_{2} \mathrm{O}_{3}$ interfaces. ${ }^{4,6}$ Although the latter two types of samples were fabricated using atomic layer deposition (ALD) of alumina at $300{ }^{\circ} \mathrm{C}$, the $\mathrm{Al}_{2} \mathrm{O}_{3} \mathrm{CB}$ bottom can still be used as a reliable reference level, as no sensitivity of interface band alignment to the high- $\kappa$ oxide growth technique is found in the case of $(100) \mathrm{Si}$ or $(100) \mathrm{Ge}$ substrates. ${ }^{9,15}$ The data shown in Fig. 4 indicate that the VB top in $\mathrm{GaSb}$ is at $\delta \mathrm{E}_{\mathrm{V}}=0.4 \mathrm{eV}$ above the $\mathrm{VB}$ of $\mathrm{In}_{\mathrm{x}} \mathrm{Ga}_{1-\mathrm{x}} \mathrm{As}$ and at $\delta \mathrm{E}_{\mathrm{V}}=1 \mathrm{eV}$ above the $\mathrm{VB}$ of InP, indicating that both of the latter semiconductors are suitable as barrier layers for fabrication of GaSb QW hole channels. This result is also consistent with the earlier inferred hole confinement potential of $0.3-0.45 \mathrm{eV}$ in GaSb quantum dots in GaAs. ${ }^{16,17}$ On the other hand, the encountered shift of $\delta \mathrm{E}_{\mathrm{V}}=0.4 \mathrm{eV}$ in the VB between GaAs and GaSb is twice as large as the theoretical prediction. ${ }^{18}$ Also, the derived $\mathrm{VB}$ offset of $3 \mathrm{eV}$ is 0.4 $\mathrm{eV}$ smaller than that reported recently for the ALD $\mathrm{Al}_{2} \mathrm{O}_{3} / \mathrm{GaSb}$ interface on the basis of XPS measurements. ${ }^{19}$ The latter discrepancy may be caused by positive charging of the oxide layer during XPS measurements due to heavy x-ray irradiation, ${ }^{9}$ which would result in a downshift of the electron energy levels in $\mathrm{Al}_{2} \mathrm{O}_{3}$ with respect to the levels in semiconductor substrate leading to a systematically larger VB offset. ${ }^{20,21}$ As the charging-induced energy shift depends on the insulator thickness, ${ }^{20}$ the results obtained in Ref. 19 for a $3 \mathrm{~nm} \mathrm{ALD} \mathrm{Al}_{2} \mathrm{O}_{3}$ layer may be reconciled with our conclusions by correcting them for $\mathrm{a} \approx 0.3 \mathrm{~V} \mathrm{CV}$ curve shift observed after exposure of a similar $3 \mathrm{~nm}$ thick ALD $\mathrm{Al}_{2} \mathrm{O}_{3}$ film to ionizing radiation (see Fig. 9 in Ref. 9).

In conclusion we have found that the $\mathrm{VB}$ of $\mathrm{GaSb}$ at the $(100) \mathrm{GaSb} / \mathrm{Al}_{2} \mathrm{O}_{3}$ interface is energetically located at $3.05 \pm 0.10 \mathrm{eV}$ below the oxide $\mathrm{CB}$ bottom, which corresponds to $\mathrm{CB}$ and $\mathrm{VB}$ offsets of $2.3 \pm 0.10$ and $3.05 \pm 0.15 \mathrm{eV}$, respectively. As compared to $\operatorname{In}_{\mathrm{x}} \mathrm{Ga}_{1-\mathrm{x}} \mathrm{As}$ $(0 \leq \mathrm{x} \leq 0.53)$ and $\mathrm{InP}$, the $\mathrm{VB}$ of GaSb lies at a considerably lower energy, indicating a significant impact of the group- $\mathrm{V}$ anion of the VB energy in $\mathrm{A}_{\mathrm{III}} \mathrm{B}_{\mathrm{V}}$ semiconductors. Therefore, the application of antimonide family semiconductor materials would enable one to engineer the hole QW channels for $\mathrm{A}_{\mathrm{III}} \mathrm{B}_{\mathrm{V}}$ complementary metal-oxide-semiconductor circuits.

${ }^{1}$ B. P. Tinkham, B. R. Bennett, R. Magno, B. V. Sanabrook, and J. B. Boos, J. Vac. Sci. Technol. B 23, 1441 (2005).

${ }^{2}$ A. Ali, H. S. Madan, A. P. Kirk, D. A. Zhao, D. A. Mourey, M. K. Hudait, R. M. Fallace, T. N. Jackson, B. R. Bennett, J. B. Boos, and S. Datta, Appl. Phys. Lett. 97, 143502 (2010).

${ }^{3}$ J. Knoch and J. Appenzeller, IEEE Electron Device Lett. 31, 305 (2010). ${ }^{4}$ V. V. Afanas'ev, A. Stesmans, G. Brammertz, A. Delabie, S. Sionke, A. O’Mahony, I. M. Povey, M. E. Pemble, E. O'Connor, P. K. Hurley, and S. B. Newcomb, Appl. Phys. Lett. 94, 202110 (2009).

${ }^{5}$ N. V. Nguyen, M. Xu, O. A. Kirillov, P. D. Ye, C. Wang, K. Cheung, and J. E. Suehle, Appl. Phys. Lett. 96, 052107 (2010).

${ }^{6}$ H.-Y. Chou, V. V. Afanas'ev, A. Stesmans, H. C. Lin, P. K. Hurley, and S. B. Newcomb, Appl. Phys. Lett. 97, 132112 (2010).

${ }^{7}$ V. V. Afanas'ev, M. Badylevich, A. Stesmans, G. Brammertz, A. Delabie, S. Sionke, A. O'Mahony, I. M. Povey, M. E. Pemble, E. O'Connor, P. K Hurley, and S. B. Newcomb, Appl. Phys. Lett. 93, 212104 (2008).

${ }^{8}$ Y. C. Chang, C. Merckling, J. Penaud, C. Y. Lu, W.-E. Wang, J. Dekoster, M. Meuris, M. Caymax, M. Heyns, J. Kwo, and M. Hong, Appl. Phys. Lett. 97, 112901 (2010).

${ }^{9}$ V. V. Afanas'ev and A. Stesmans, J. Appl. Phys. 102, 081301 (2007).

${ }^{10} \mathrm{~V}$. V. Afanas'ev, Internal Photoemission Spectroscopy (Elsevier, Amsterdam, 2008).

${ }^{11}$ D. E. Aspnes and A. A. Studna, Phys. Rev. B 27, 985 (1983).

${ }^{12}$ V. I. Gavrilenko, A. M. Grekhov, D. V. Korbutyak, and V. G. Litovchenko, Optical Properties of Semiconductors (Naukova Dumka, Kiev, 1987).

${ }^{13}$ V. V. Afanas'ev, A. Stesmans, R. Droopad, M. Passlack, L. F. Edger, and D. G. Schlom, Appl. Phys. Lett. 89, 092103 (2006)

${ }^{14}$ R. J. Powell, J. Appl. Phys. 41, 2424 (1970).

${ }^{15}$ V. V. Afanas'ev, A. Stesmans, A. Delabie, F. Bellenger, M. Houssa, R. R. Lieten, C. Merckling, J. Penaud, D. P. Brunco, and M. Meuris, Mater. Sci. Semicond. Process. 11, 230 (2008).

${ }^{16}$ M. Geller, C. Kapteyn, L. Muller-Kirsch, R. Heintz, and D. Bimberg, Appl. Phys. Lett. 82, 2706 (2003).

${ }^{17}$ R. Timm, H. Eisele, A. Lenz, L. Ivanova, V. Vosseburger, T. Warming, D. Bimberg, I. Farrer, D. A. Ritchie, and M. Dahne, Nano Lett. 10, 3972 (2010).

${ }^{18}$ J. Robertson and B. Falabretti, J. Appl. Phys. 100, 014111 (2006).

${ }^{19}$ I. Geppert, M. Eizenberg, A. Ali, and S. Datta, Appl. Phys. Lett. 97, 162109 (2010).

${ }^{20}$ M. Perego, G. Seguini, and M. Fanciulli, Mater. Sci. Semicond. Process. 11, 221 (2008).

${ }^{21}$ E. Bersch, M. Di, S. Consiglio, R. D. Clark, G. J. Leusink, and A. C. Diebold, J. Appl. Phys. 107, 043702 (2010). 